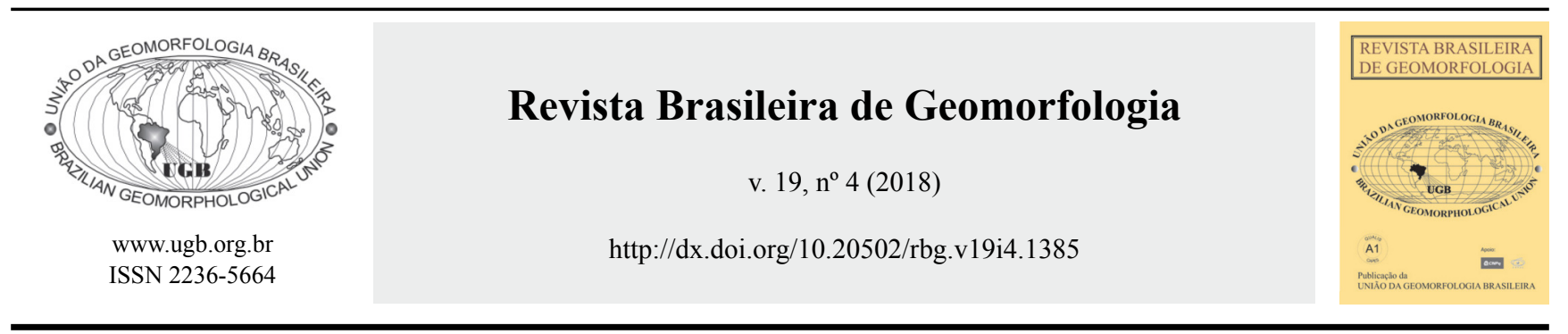

NOTE TÉCNICA:

\title{
MAPEAMENTO DIGITAL DE SOLOS E OS ATRIBUTOS TOPOGRÁFICOS DAS VERTENTES NO ALTO CURSO DA SUB-BACIA HIDROGRÁFICA DO CÓRREGO QUATRO PONTES, PR-BRASIL
}

\section{DIGITAL SOIL MAPPING AND THE TOPOGRAPHIC ATTRIBUTES OF THE SLOPE IN THE HIGH COURSE OF THE SUB-BASIN HYDROGRAPHIC FROM QUATRO PONTES STREAM, PR-BRAZIL}

\author{
Bruno Aparecido da Silva \\ Programa de Pós-graduação em Geografia - UNIOESTE \\ Francisco Beltrão - Rua Maringá, 1200 - PR - Brasil \\ E-mail: brunoborchertesilva@gmail.com
}

Vanda Moreira Martins

Programa de Pós-graduação em Geografia - UNIOESTE Marechal Cândido Rondon - Rua Pernambuco, 1777 - PR - Brasil

E-mail:mmvanda@hotmail.com

Ericson Hideki Hayawaka

Programa de Pós-graduação em Geografia - UNIOESTE Marechal Cândido Rondon - Rua Pernambuco, 1777 - PR - Brasil

E-mail: ericson.geo@gmail.com

Rodrigo Santana Macedo

Instituto Nacional do Semiárido (INSA)

Campina Grande, PB - Brasil

E-mail:macedo-rs@hotmail.com

\begin{tabular}{l} 
Informações sobre o Artigo \\
\hline Recebido (Received): \\
24/01/2018 \\
Aceito (Accepted): \\
10/07/2018 \\
\hline
\end{tabular}

Palavras-chave:

Pedometria; Mapa de solos; SRTM.

\section{Keywords:}

Pedometry; Soil map; SRTM.

\section{Resumo:}

Na região Oeste do Paraná, a expansão urbana e a agrícola apontam para a necessidade de mapeamentos detalhados de solos, assim como em grande parte do território brasileiro. O decreto n. 9.414, de 20 de junho de 2018, que instituiu o Programa Nacional de Levantamento e Interpretação de Solos do BrasilPronasolos é uma das consequências políticas desse processo. Indispensável ao planejamento do uso e manejo urbano e rural do solo que, no município de Quatro Pontes-PR, ocorre, em teoria, sob o amparo da legislação ambiental e municipal, o mapa detalhado dos solos é um documento cartográfico essencial. Assim, foi proposta a elaboração do mapeamento digital do solo (MDS), em escala 1:50.000, do alto curso do córrego Quatro Pontes. O objetivo foi avaliar 
a correspondência espacial das classes de solos em relação ao Mapeamento Convencional de Solos (MCS) do referido setor. Os dados do SRTM (Shuttle Radar Topography Mission) auxiliaram no MDS. A partir destes foram gerados os atributos topográficos de altimetria, declividade, curvatura da vertente e o Índice de Capacidade de Transporte de Sedimentos. A álgebra dos atributos topográficos primários e secundários foi utilizada para realizar o MDS da sub-bacia. Verificou-se que os LATOSSOLOS VERMELHOS (LV) dominam os segmentos estáveis dos interflúvios com declividade $<3 \%$ e curvatura retílinea-divergente. Nos segmentos médios e inferiores das vertentes, com declividade entre 3 e $20 \%$, ocorrem os NITOSSOLOS VERMELHOS (NV). Nos segmentos mais dissecados e nos fundos de vale ( $>20 \%$ de declividade), ocorre a associação de NEOSSOLO REGOLÍTICO (RR) + NEOSSOLO LITÓLICO (RL) + CAMBISSOLO HÁPLICO (CX), enquanto que, próximos aos canais fluviais e alguns setores sujeitos a hidromorfia ocorrem os GLEISSOLOS HÁPLICOS (GX). A álgebra entre o MCS e o MDS indicou uma correspondência espacial com exatidão global de $66 \%$ entre as classes de solos mapeadas. Os resultados mais precisos no MDS estão relacionados aos LATOSSOLOS VERMELHOS, NITOSSOLOS VERMELHOS e GLEISSOLOS HÁPLICOS.

\begin{abstract}
:
In the western region of Paraná, urban and agricultural expansion point to the need for detailed mapping of soils, as well as in much of the Brazilian territory. Decree no. 9,414 of June 20, 2018, which instituted the Brazilian Soil Survey and Interpretation Program of Brazil-Pronasolos, is one of the political consequences of this process. Indispensable to the urban and rural land use and management planning that, in theory, under the protection of environmental and municipal legislation, in the municipality of Quatro Pontes-PR, the detailed map of the soils is an essential cartographic document. Thus, it was proposed the elaboration of the Digital Soil Mapping (DSM), in scale 1: 50,000, of the Upper Quatro Pontes River. The main was to evaluate the spatial correspondence of the soil classes in relation to the Conventional Soil Mapping (CSM) of this sector. SRTM (Shuttle Radar Topography Mission) data aided the DSM. From these, the topographic attributes of altimetry, slope, curvature and Sediment Transport Capacity Index were generated. The algebra of the primary and secondary topographic attributes was used to perform the DSM of the sub-basin. Ferralsols have been found to dominate the stable segments of interfluves with slope $<3 \%$ and retreat-divergent curvature. In the middle and lower segments of the slopes, with slope between 3 and $20 \%$, Nitisols occur. In the most dissected segments and in the bottom of the valley ( $>20 \%$ of slope), there is the association of Regosols + Leptosols + Cambisols, while, close to the fluvial channels and some sectors subject to hydromorphic occur the Gleysols. The algebra between the CSM and the DSM indicated a spatial match with global accuracy of $66 \%$ among the classes of soils mapped. The most accurate results in the DSM are related to Ferralsols, Nitisols and Gleysols.
\end{abstract}

\section{Introdução}

Os mapas pedológicos fornecem informações primárias que subsidiam o planejamento do uso, ocupação e manejo dos solos de um país (DEBELLAGILO e ETZELMÜLLER, 2009). Burrough (1993) e Brungard et al. (2015) destacam a importância de sistematizar informações sobre a distribuição espacial dos solos, auxiliando no gerenciamento do território. Atualmente, duas são as abordagens em mapeamentos de solos utilizadas em escala detalhada: o Mapeamento Convencional de Solos (MCS) e o Mapeamento Digital de Solos (MDS). A principal diferença entre as duas técnicas é que no MCS o modelo solo-paisagem é qualitativo, baseado na experiência do mapeador, enquanto que no MDS o modelo solo-paisagem é quantitativo (KEMPEN et al., 2011).

Os MCS são elaborados a partir das interações entre os elementos da paisagem. As fotografias aéreas e cartas topográficas fornecem os dados e as informações básicas dos atributos pedogeomorfológicos, permitindo as interpretações e inferências sobre a distribuição espacial dos solos. As observações e descrições morfológicas dos perfis de solos representativos das unidades de mapeamento são etapas essenciais na elaboração dos mapas convencionais de solo (EMBRAPA, 1995; KEMPEN et al., 2011). No entanto, 
o método convencional exige elevado custo financeiro decorrente da necessidade numérica de recursos humanos capacitados, infraestrutura adequada, além da demanda de tempo e disponibilidade de dados cartográficos. Neste contexto, o MDS tornou-se a alternativa mais viável para mapear a distribuição espacial dos solos, difundindo-se a partir da popularização das técnicas e ferramentas de geotecnologias (MCBRATNEY et al., 2003; DEBELLAGILO e ETZELMÜLLER, 2009), as quais também contribuíram para o aperfeiçoamento desse tipo de mapeamento (DOBOS et al., 2000; LEPSCH, 2011).

O MDS foi sistematizado a partir de modelos determinísticos desenvolvidos por McBratney et al. (2003), embora Moore et al. (1993) já tenham destacado a importância da Pedometria na inferência da distribuição espacial dos solos, a partir de atributos topográficos do terreno. Estes últimos acrescentam que, de posse de informações referentes à configuração morfológica de uma vertente, é possivel compreender os processos pedogenéticos. Adicionalmente, em função dos menores custos do MDS, em relação ao método convencional, diversos pesquisadores têm se apoiado em técnicas da Pedometria para predizer a distribuição espacial dos solos, tais como Moore et al. (1993), Gessler (2000), McBratney (2000; 2003), Sirtoli et al. (2008a, b), Debella-Gilo e Etzelmüller (2009), Silveira (2010), Kempen et al. (2011), Silveira et al. (2012, 2013), Nowatzki (2013), Lima et al. (2014), Brungard et al. (2015), Silva (2017a).

Aregião Oeste do Estado do Paraná, especificamente a área que compreende a Bacia Hidrográfica do Paraná 3 (BP3), a qual congrega diversas sub-bacias hidrográficas cujos canais principais deságuam no reservatório de Itaipu, destaca-se no cenário agropecuário regional e nacional. Os atributos dos solos e da topografia favorecem a mecanização agrícola na maior parte de sua área. Contudo, instituições como a Itaipu Binacional e as prefeituras municipais demandam de informações pedológicas e mapeamentos de solos detalhados que sirvam de base para o manejo adequado e a conservação dos solos na BP3. O mapa de solos disponível para a região é o oriundo da EMBRAPA (1984), em escala 1:250.000 e não aparesenta nível de detalhamento adequado para sua utilização na esfera do município ou da sub-bacia hidrográfica. Esta conjuntura não é apenas local ou regional, havendo poucos mapas de solos em escala mais detalhada que 1:50.000 no Brasil.
Realidade esta que tem preocupado os cientistas dos solos e outros seguimentos da sociedade (LEPSCH, 2013). Com a retomada nacional da realização de levantamentos pedológicos em caráter multiescalar, a partir do Pronasolos, parte dessa deficiência deverá ser sanada (POLIDORO et al., 2016).

A elaboração de mapas convencionais em escalas aproximadas de 1:50.000 e de mapas digitais de solos na BP3 tem sido objeto de recentes pesquisas (JANJAR, 2013, DANZER, 2015; SILVA et al., 2016; SILVA 2017). Comumente os estudos pedogeomorfológicos desenvolvidos na área tiveram como enfoque a descrição de atributos morfológicos do relevo como condicionantes da distribuição dos solos na paisagem (e.g. MORESCO, 2007; JANJAR, 2013; ROCHA et al., 2012; MAGALHÃES et al., 2012, 2013 e 2016; CALEGARI e MARCOLIN, 2014; DANZER, 2015).

A proposta deste trabalho, por sua vez, foi elaborar o MDS, em escala aproximada de 1:50.000, do alto curso da sub-bacia do Córrego Quatro Pontes no município homônimo, localizado na BP3, região Oeste do Paraná. O objetivo foi avaliar a correspondência espacial entre o MDS e o MCS. Este último, elaborado por Silva et al. (2016). Atualizar o mapeamento convencional no referido setor da sub-bacia também está entre os objetivos do trabalho.

Cabe ressaltar que, uma vez que as técnicas de pedometria (MDS) têm sido satisfatórias ao serem utilizadas para predizer a distribuição geográfica dos solos em paisagens de outras regiões (SIRTOLI et al., 2008a, b; SILVEIRA et al., 2012, 2013; NOWATZKI, 2013), busca-se difundir o MDS, bem como replicar essas técnicas na BP3, uma vez que podem contribuir para o melhor entendimento da dinâmica pedogeomorfológica do ponto de vista do uso e manejo do solo, além de agilizar a elaboração dos mapas de solos em escalas de 1:50.000.

\section{Localização e Caracterização da Área de Estudo}

A área de estudo (alto curso da sub-bacia do Córrego Quatro Pontes) localiza-se na região Oeste do estado do Paraná (Figura 1) e se insere na Bacia do Paraná 3 (BP3), abrangendo uma área de $34,24 \mathrm{~km}^{2}$. A litologia é constituída por rochas basálticas do Grupo Serra Geral (MINEROPAR, 2013), originadas durante o Período Cretáceo (NARDY et al., 2002). O clima é 
do tipo $\mathrm{Cfa}$, moderadamente quente, com temperatura média no verão superior a $22^{\circ} \mathrm{C}$ e média no inverno inferior a $18^{\circ} \mathrm{C}$ (PARANÁ, 2013). A ausência de estação seca definida e o regime de distribuição anual da precipitação (> $1500 \mathrm{~mm} / \mathrm{ano}$ ), aliadas à geologia local favorecem a formação de uma rede hidrográfica composta por canais fluviais perenes.

A interação entre a litologia e o clima deu origem ao relevo com formas predominantemente suaveonduladas e declividade entre $0-8 \%$, caracterizado por extensos e planos interflúvios ( $<3 \%$ ) e fundos de vales em forma de $\mathrm{V}$ abertos ou encaixados (SANTOS et al., 2006). A sub-bacia selecionada encontra-se no Planalto de Cascavel, Unidade de Marechal Cândido Rondon (BADE et al., 2016), com altitudes entre 220 (calha do rio Guaçu) e 500 metros. As vertentes são retilíneas/ convexas nos interflúvios, retilíneas nas médias vertentes e côncavas nos compartimentos de fundo de vales. Considerado um importante fator de formação dos solos, o relevo condiciona a organização vertical e lateral dos horizontes, bem como a distribuição espacial das classes de solos que compõem a paisagem regional, entre eles os Latossolos Vermelhos, os Nitossolos Vermelhos, os Neossolos Regolíticos, os Gleissolos Háplicos e os Cambissolos Háplicos (BHERING et al., 2007).

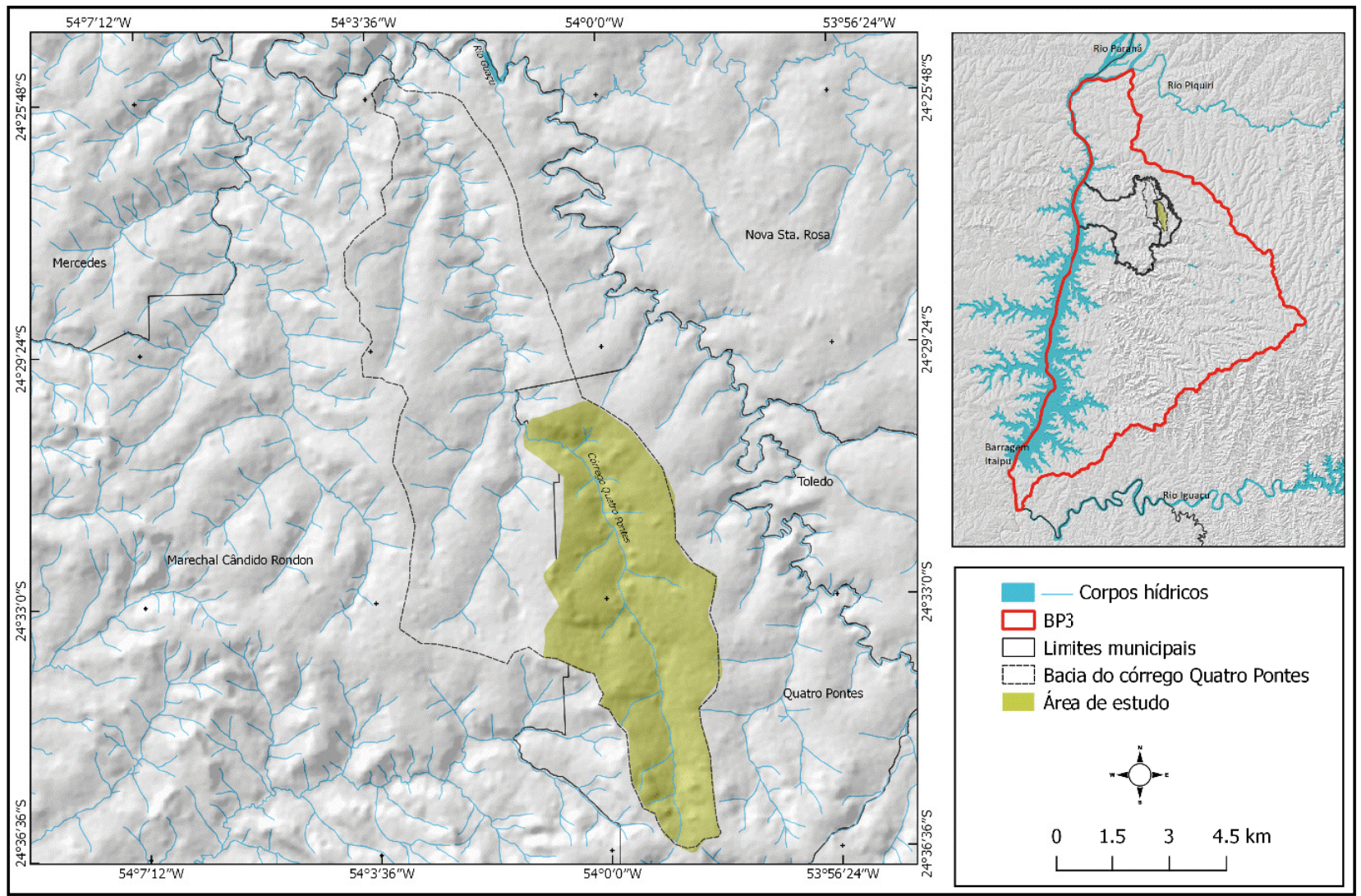

Figura 1 - Localização do alto curso da sub-bacia do Córrego Quatro Pontes na região Oeste do Paraná-BR.

\section{Material e Métodos}

Os materiais utilizados e as fontes de informação para o desenvolvimento desta pesquisa estão apresentados no Quadro 1.

\subsection{Mapeamento Convencional de Solos (MCS)}

O Mapeamento Convencional de Solos (MCS) da área de estudo, em escala 1:50.000, foi elaborado por
Silva (2016), o qual mapeou cinco unidades simples: LATOSSOLOS, NITOSSOLOS, CAMBISSOLOS, GLEISSOLOS e NEOSSOLOS. A atualização desse mapa de solos pautou-se em observações e descrição de solos em campo, as quais foram realizadas por meio de caminhamento livre ao longo das vertentes (do topo para o fundo de vale). As aferições das transições entre as classes de solos (EMBRAPA, 1995) na vertente foram realizadas a partir de tradagens, para 
identificação da cor (carta de Munsell), da textura e dos horizontes pedogenéticos. A descrição morfológica dos horizontes dos solos foi realizada em barrancos e corte de estradas, onde foram realizadas descrições completas do perfil, conforme propõe Santos et al. (2015). Os solos foram identificados e classificados até o segundo nível categórico (EMBRAPA, 2013). Com a atualização do mapa foram mapeadas quatro unidades, sendo três simples e uma associação: LATOSSOLOS VERMELHOS (LV), NITOSSOLOS VERMELHOS (NV), GLEISSOLOS HÁPLICOS (GX) e NEOSSOLOS REGOLÍTICOS (RR) + NEOSSOLOS LITÓLICOS (RL) + CAMBISSOLOS HÁPLICOS (CX). A aferição e correção dos limites entre as unidades de mapeamento foi realizada por meio de edição vetorial no software Qgis 2.10.

Quadro 1: Materiais utilizados para o desenvolvimento do MCS e MDS no alto curso da sub-bacia do Córrego Quatro Pontes.

\begin{tabular}{|c|c|}
\hline Fonte & Dados \\
\hline $\begin{array}{c}\text { IBGE http://www.ibge.gov.br } \\
\text { LNPE-TOPODATA - Banco de Dados } \\
\text { Geomorfométricos do Brasil } \\
\text { www.dsr.inpe.br/topodata/ }\end{array}$ & Limites municipais e estaduais \\
\hline $\begin{array}{c}\text { USGS } \\
\text { https://earthexplorer.usgs.gov }\end{array}$ & Curvatura do terreno: 24S555FT (1:250.000) \\
\hline $\begin{array}{c}\text { Lab. Geoprocessamento e Cartografia- } \\
\text { UNIOESTE }\end{array}$ & Amagens SRTM (30 metros de resolução): S25W54 e S25W55 10.4 \\
\hline $\begin{array}{c}\text { Comunidade Qgis http://qgisbrasil.org/ } \\
\text { Saga } \underline{\text { https://sagagisbrasil.wordpress.com }}\end{array}$ & QGis 2.10 e Saga 2.2.6 \\
\hline
\end{tabular}

\subsection{Mapeamento Digital de Solos (MDS)}

Os atributos topográficos primários (Declividade e Curvatura do Terreno) e secundário (Índice de Capacidade de Transporte de Sedimentos - ICTS) foram as variáveis utilizadas no MDS. Os dados de declividade foram obtidos do Modelo Digital de Elevação proveniente do SRTM (Shuttle Radar Topography Mission), cuja resolução espacial é de 30 metros, disponível no site Earth Explorer (USGS, 2017). Os dados de Curvatura do terreno estão disponíveis no site do TOPODATAINPE. A manipulação das informações de declividade e curvatura ocorreu no software QGis 2.10 e as classes foram estabelecidas conforme EMBRAPA (2013) e Valeriano (2008), respectivamente. O atributo topográfico secundário ICTS foi obtido a partir dos dados SRTM no software Saga 2.2.6 e indica as áreas com possível rejuvenescimento do solo (SILVEIRA et al., 2012 e 2013) ou situações de estabilidade e instabilidade do terreno. Esse índice foi obtido a partir da equação abaixo em que o ICTS é o Índice de Capacidade de Transporte de Sedimentos; As é a Área de contribuição e $\operatorname{sen} \beta$ é a Declividade expressa em radianos:

$$
\operatorname{ICTS}=(\operatorname{As} / 22.13)^{0,6} \times(\operatorname{sen} \beta / 0,0896)^{1,3}
$$

Após a discretização das classes dos atributos topográficos foram atribuídos pesos a cada uma delas, conforme a importância da informação em relação a outra, considerando a atuação da pedogênese (pesos 1 e 2) e da morfogênese (peso 3) (Tabela 1). De modo geral, pesos inferiores indicam o prevalecimento da pedogênese sobre a morfogênese, com presença de topos planos e alongados, suave ondulados, vertentes amplas, retilíneas e convexas de declividade até $3 \%$. No peso 2 a morfogênese se sobrepõe parcialmente à pedogênese, com vertentes de declividade entre 3 e $20 \%$ e ICTS 2 . Já no peso 3, a morfogênese é majoritária em detrimento da pedogênese, com vertentes convexas de declividade acima de $20 \%$ e relevo forte ondulado e ICTS 3.

O MDS foi obtido da álgebra entre atributos topográficos primários e secundários, conforme procedimentos adotados por Silveira (2010), Silveira et al. (2012 e 2013) e Nowatzki (2013). No software ArcGis 10.4, por meio da função Spatial Analyst, foram geradas quatro (04) unidades de mapeamento, as quais, posteriormente, foram associadas às classes de solos do Mapa Convencional de Solos. A equação abaixo exemplifica a álgebra de mapas para a elaboração do MDS:

MDS $=($ Declividade $\mathrm{x}$ Curvatura $\mathrm{x}$ ICTS $)$ 
Tabela 1: Síntese das classes de Declividade, Curvatura do Terreno e Índice de Capacidade de Transporte de Sedimentos (ICTS) e seus respectivos pesos atribuídos.

\begin{tabular}{|c|c|c|c|}
\hline \multicolumn{2}{|c|}{ Declividade } & \multicolumn{2}{|c|}{ Curvatura do Terreno } \\
\hline Classes & Peso $^{1}$ & Classes $^{2}$ & Peso \\
\hline $0-3$ & 1 & $\mathrm{C}-\mathrm{Cv}$ & 3 \\
\hline 3-8 & 2 & $\mathrm{C}-\mathrm{R}$ & 3 \\
\hline 8-20 & 2 & $\mathrm{C}-\mathrm{Cx}$ & 3 \\
\hline$>\mathbf{2 0} \%$ & 3 & $\mathrm{R}-\mathrm{Cv}$ & 3 \\
\hline \multicolumn{2}{|c|}{ ICTS } & R-R & 1 \\
\hline Classes & Peso & $\mathrm{R}-\mathrm{Cx}$ & 1 \\
\hline ICTS 1 & 1 & $\mathrm{D}-\mathrm{Cv}$ & 1 \\
\hline ICTS 2 & 2 & D-R & 1 \\
\hline ICTS 3 & 3 & $\mathrm{D}-\mathrm{Cx}$ & 1 \\
\hline
\end{tabular}

${ }^{1}$ Pesos estabelecidos entre relação Pedogênese (Pesos 1 e 2)/Morfogênese (Peso 3).

${ }^{2} D-C v$ : Divergente-Côncavo; D-R: Divergente-Retilineo; D-Cx: Divergente-Convexo; $R-C v$ : Retilineo-Côncavo; R-R: Retilíneo-Retilíneo; $R$-Cx: Retilineo-Convexo; C-Cv: Convergente-Côncavo; $C-R$ : Convergente-Retilíneo, e; C-Cx: Convergente-Convexo.

Em seguida, realizou-se a álgebra entre o MCS (mapa de referência) e o MDS no software Arc Gis 10.4. Os valores obtidos foram organizados numa matriz de erros para determinar o percentual de correspondência entre o mapa gerado (MDS) em relação ao mapa de referência (MCS), a partir dos valores de Erros de inclusão (Eic); Erros de omissão (Eom); Erros do Usuário (EU) e Erros do
Produtor (EP). Os EU se referem à correspondência entre a classe de solos do mapa gerado (imagem) e essa mesma classe no mapa de referência, em que quanto maior a taxa de EU, menos erros de inclusão ocorreram; enquanto os EP se referem às classes corretamente classificadas e, portanto, quanto menor a omissão de pixels de uma determinada classe, maior será o EP (Tabela 2).

Tabela 2: Matriz de erros referente à correspondência entre o MCS e o MDS do alto curso da sub-bacia do córrego Quatro Pontes.

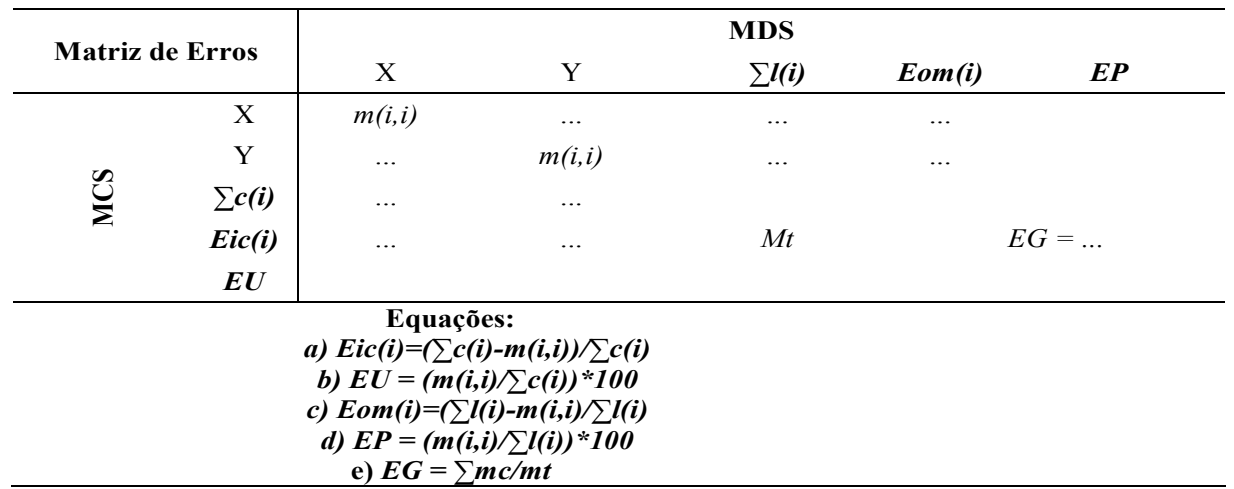

Eic(i) - Erros de inclusão. $\sum \boldsymbol{c}(\boldsymbol{i})$ - Somatório da coluna. m(i,i) - elementos da diagonal da linha (i) da matriz de erros. EU - Ponto de

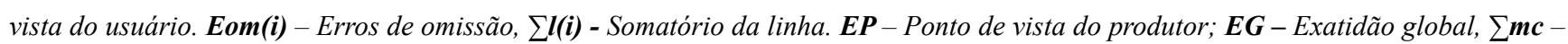
Somatório de elementos da diagonal da linha (i) da matriz de erros corretamente classificados, mt - Total de elementos (pontos). Fonte: Adaptado de Silveira (2010) e Nowatzki (2013).

\section{Resultados e Discussão}

\subsection{Atributos Topográficos}

O alto curso da sub-bacia do Córrego Quatro Pontes apresenta altitudes que variam entre 525 metros, no setor
Sul, e $320 \mathrm{~m}$ à jusante (foz da sub-bacia). Ao longo do canal principal, com $11 \mathrm{~km}$ de comprimento, os vales são mais dissecados pela rede de drenagem entre as cotas de 320-375 m e de 400-450 m, enquanto os setores com cotas entre 375 e 400 m os vales são abertos e achatados 
(Figura 2). Essas diferenças na dissecação dos vales estão relacionadas com a interação entre a rede de drenagem e as camadas do basalto que formam o substrato litológico na região (EWALD e FERNANDES, 2012).

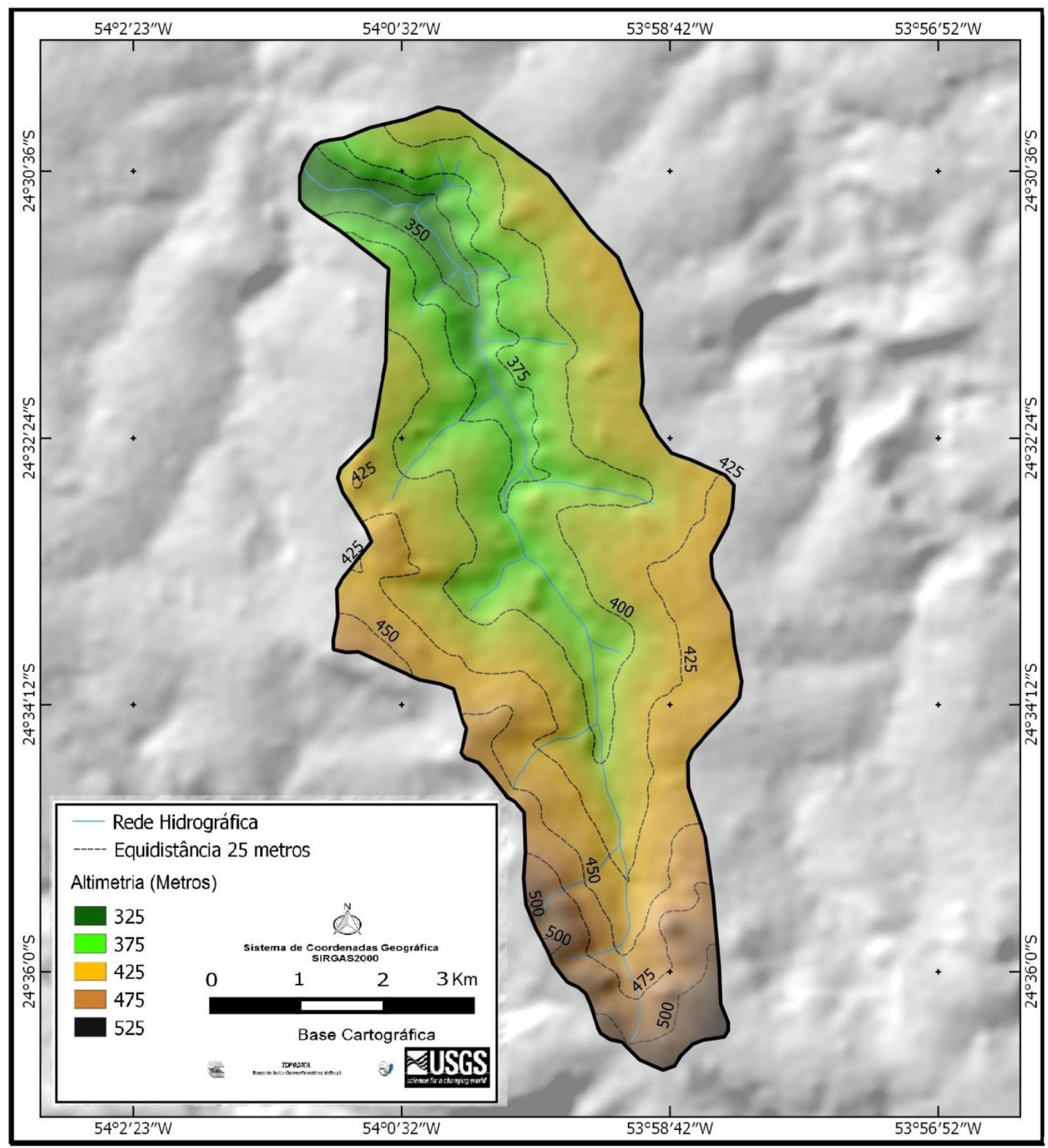

Figura 2 - Mapa de altimetria do alto curso da sub-bacia do Córrego Quatro Pontes.

$\mathrm{Na}$ área de estudo predomina o relevo plano a suave ondulado com declividades $\leq 8 \%$, associadas, principalmente, aos extensos interflúvios e segmentos de alta vertente, bem como aos segmentos de fundo de vale, frequentemente, abertos. As classes de declividade entre 8 e 20\% associam-se aos diversos segmentos da vertente, em estreita relação com o seu comprimento e forma. Quanto mais curto e convexo for o segmento de vertente, maior é a declividade. Essa interação reflete o relevo mais dissecado e ondulado ( $>20 \%$ de declividade) em aproximadamente $20 \%$ da área do alto curso da sub-bacia do córrego Quatro Pontes. O relevo forte ondulado ocupa $<1 \%$ da área. As declividades entre 20 e 45\% (Tabela 3 e Figura 3) ocorrem em segmentos de ruptura de declive acentuadas e curtas $(<50 \mathrm{~m})$, estando relacionadas à transição entre as camadas (trapp) dos derrames basálticos que, superpostas, e entalhadas pela rede de drenagem, formam a base do relevo regional (EWALD e FERNANDES, 2012). 
Silva B. A. et al.

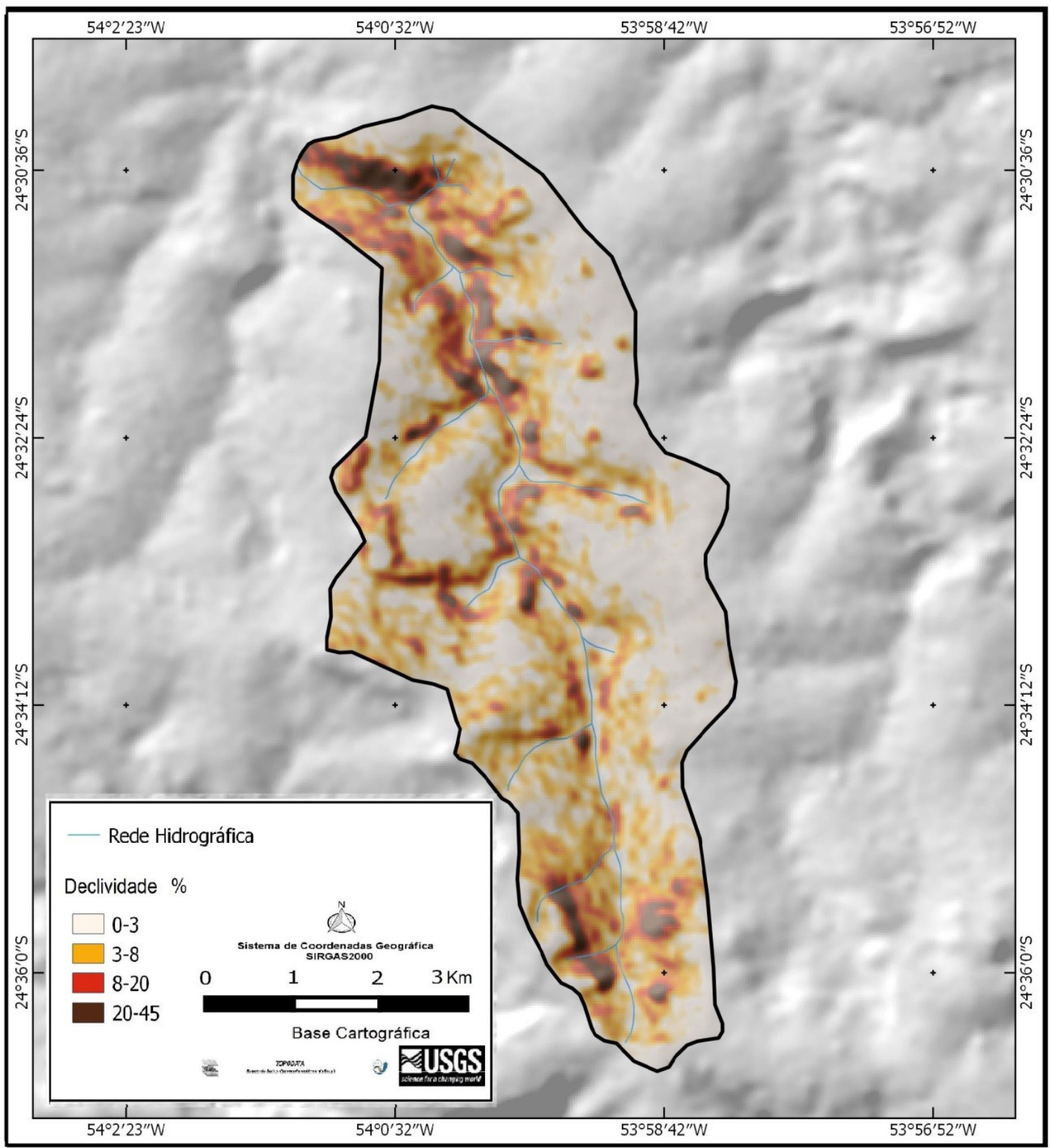

Figura 3 - Mapa de declividade do alto curso da sub-bacia do Córrego Quatro Pontes.

Tabela 3: Representatividade percentual dos atributos topográficos do alto curso da sub-bacia do Córrego Quatro Pontes.

\begin{tabular}{|c|c|c|c|}
\hline \multicolumn{2}{|c|}{ Declividade } & \multicolumn{2}{|c|}{ Curvatura do Terreno } \\
\hline Classes & Área (\%) & Classes & Área (\%) \\
\hline $0-3 \%$ & 42,8 & 1 & 7,27 \\
\hline 3 a $8 \%$ & 36,6 & 2 & 25,76 \\
\hline 8 a $20 \%$ & 20,1 & 3 & 0,72 \\
\hline$>20 \%$ & 0,5 & 4 & 2,10 \\
\hline \multicolumn{2}{|c|}{ ICTS } & 5 & 22,93 \\
\hline Classes & Área (\%) & 6 & 0,83 \\
\hline ICTS 1 & 37,5 & 7 & 1,76 \\
\hline ICTS 2 & 46,4 & 8 & 33,12 \\
\hline ICTS 3 & 16,0 & 9 & 5,50 \\
\hline
\end{tabular}


As classes de curvaturas do terreno (Figura 4) indicam que as formas predominantes na área são as retilíneas e suas variações (retilíneo-côncavo, retilíneoretilíneo e retilíneo-convexo), as quais representam mais de $80 \%$ do alto curso da sub-bacia em questão. A distribuição das formas retilíneas na paisagem está associada, principalmente, aos segmentos de interflúvio e transição com a alta vertente. A curvatura convergente-côncava, representa $7,27 \%$ da área e a divergente-convexo $5,5 \%$. A primeira está presente principalmente nos fundos de vale, enquanto a segunda está associada as áreas de alta e média vertente. As demais classes de curvatura representam apenas $5,42 \%$ da área do estudo.

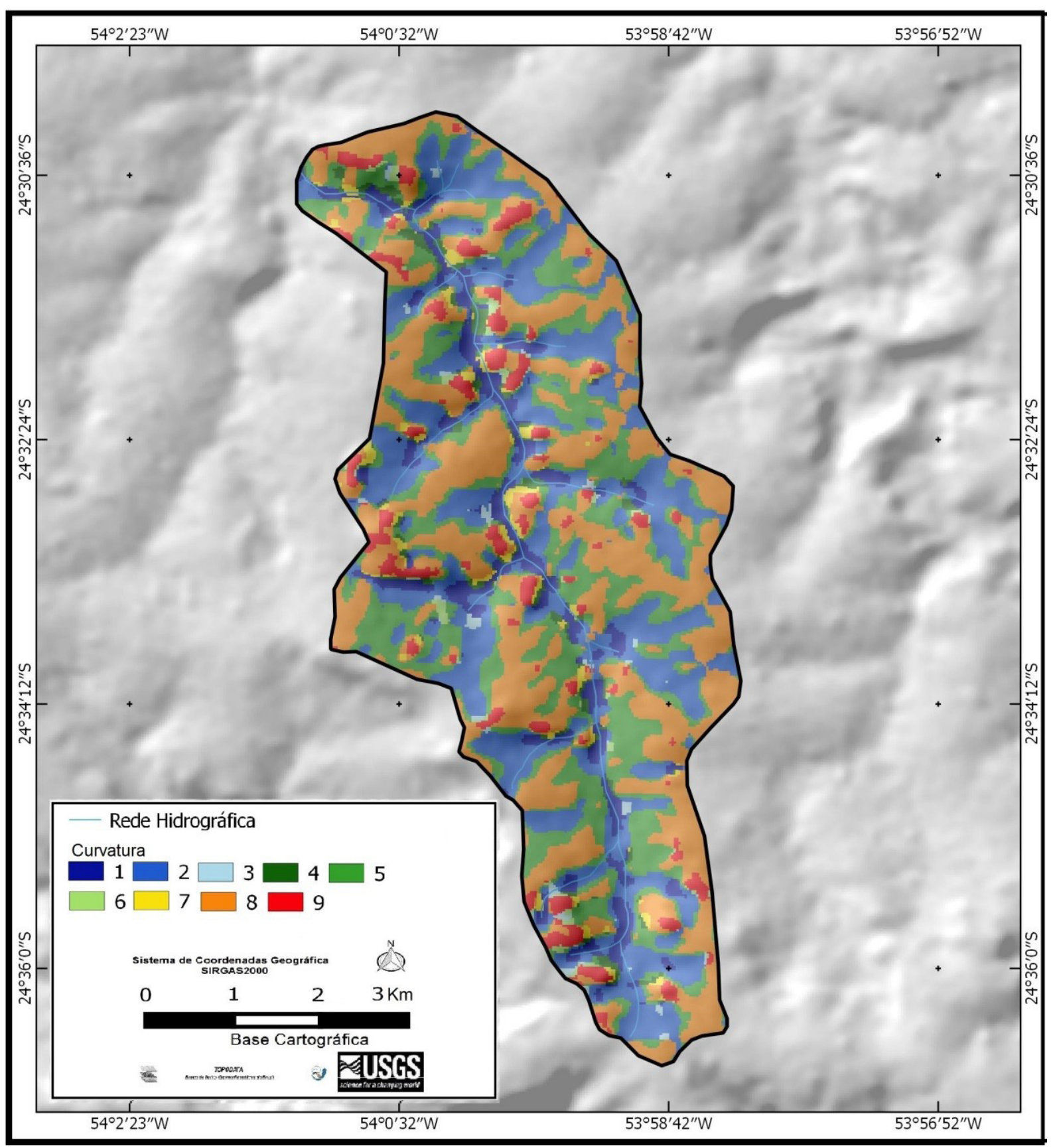

Figura 4 - Mapa da curvatura do terreno do alto curso da sub-bacia do Córrego Quatro Pontes.

O Índice de Capacidade de Transporte de Sedimentos foi definido para indicar situações de estabilidade e instabilidade do terreno (potencial erosivo).
Cerca de $16 \%$ da área foram classificadas como instáveis e $84 \%$ como estáveis em relação à erosão hídrica (Figura 5). Nota-se que os segmentos de vertente com ICTS 
1 correspondem a $37,5 \%$ da área e se localizam nos interflúvios com predomínio das curvaturas retilíneas e declividades entre 0 e $3 \%$, de modo que a pedogênese prevalece sobre a morfogênese. Nestes setores da paisagem, consideradas estáveis em relação ao ICTS 3, as classes dos LV são comuns. Gerrard (1993) ressalta a interação entre a pedogênese progressiva e a ocorrência de solos profundos, tais como os LV e os NV descritos nas posições mais estáveis da paisagem da sub-bacia. O ICTS 2 corresponde a $46,4 \%$ da área e distribui-se nos segmentos de média vertente, desde a cabeceira até a foz da sub-bacia. Nesses segmentos a declividade é superior a 3\% e a influência da morfogênese se sobrepõe a pedogênese em relação aos segmentos com ICTS 1. Os NV são comuns nestes setores cuja estabilidade tende a ser menor a medida que a declividade aumenta.

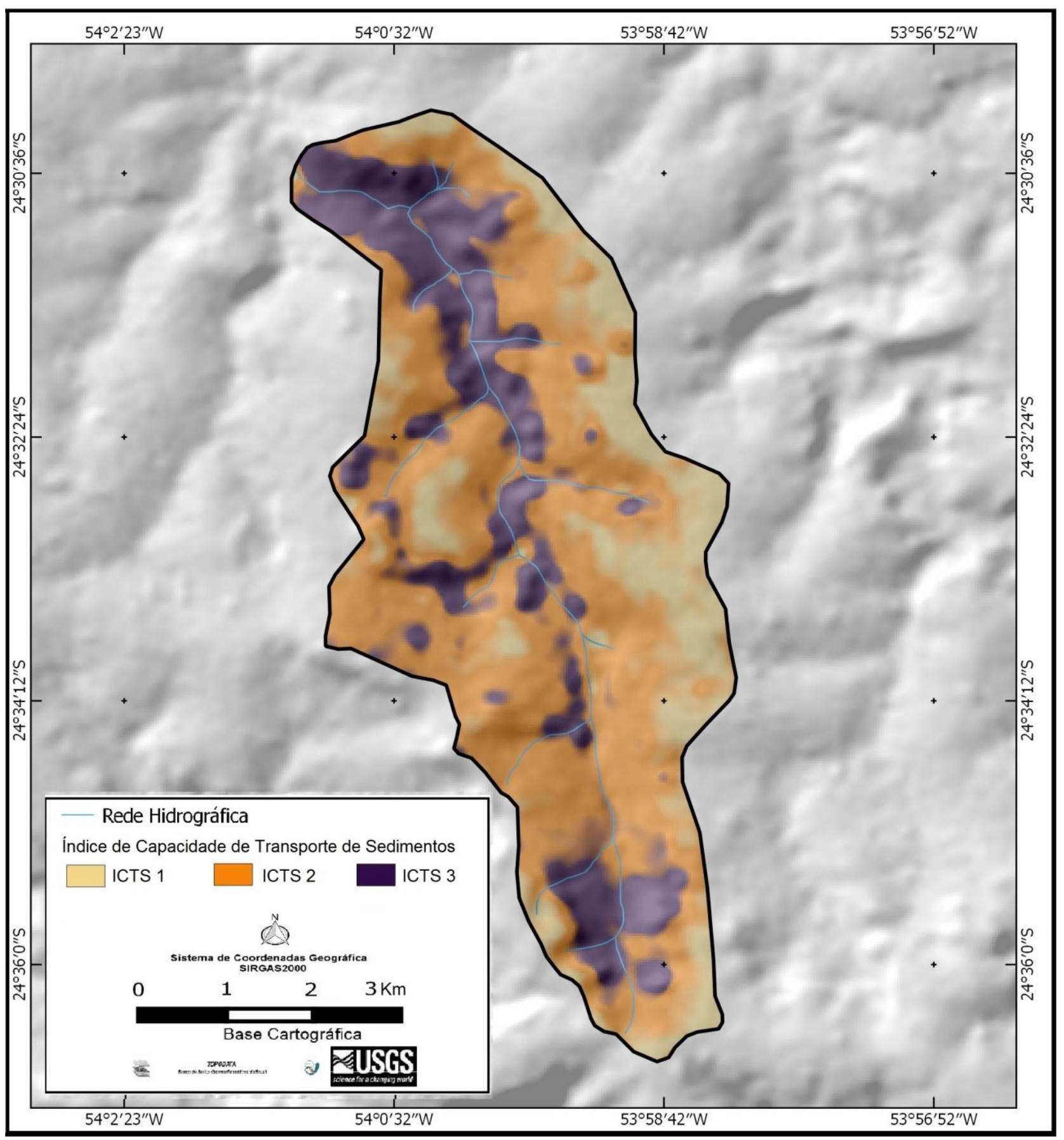

Figura 5 - Mapa do Índice de Capacidade de Transporte de Sedimentos (ICTS) do alto curso da sub-bacia do Córrego Quatro Pontes. 
Quanto aos setores associados ao ICTS 3 (16\% da área), são considerados instáveis em relação aos ICTS 1 e 2 , porque a morfogênese prevalece em detrimento da pedogênese. Este índice ocorre nos segmentos de baixa vertente dos setores norte e sul da sub-bacia, em que a morfologia das vertentes restringe a pedogênese. As declividades mais acentuadas tendem a intensificar a capacidade de transporte de sedimentos (morfogênese) e o adelgaçamento do perfil de solo. O resultado é a formação de solos rasos (RL, RR e CX) em que a morfogênese se sobrepõe à pedogênese.

\subsection{Morfologia e a distribuição dos solos}

Os mapas de solos obtidos pelo método convencional e digital evidenciaram resultados distintos de área abrangida por classe de solo (Tabela 4) e na sua distribuição espacial (Figura 6). As principais classes de solos mapeadas foram as dos LV, NV, CX, RR e NL.

No MCS os LV ocupam $44 \%$ da área da subbacia, o que corresponde a $15,6 \mathrm{~km}^{2}$. No MDS, a representatividade dessa classe foi de $21,5 \%$, ou 7,6 $\mathrm{km}^{2}$. Os LV ocupam os setores de interflúvio e a alta vertente, comumente relacionados com relevo plano e suave ondulado, declividade baixa, curvaturas retilíneas convexas, predominantemente, e ICTS 1 . No setor oeste da sub-bacia (margem esquerda do canal), a área de ocorrência dos LV no MDS é menor quando comparado ao MCS. A interação dos LV com a declividade é a causa do desajuste entre as áreas mapeadas no MCS e no MDS. No MDS a ocorrência dos LV ficou associada as declividades entre 0 e $3 \%$, enquanto no MCS foi até $6 \%$, conforme adotado por Silva et al. (2016). Na margem direita do canal principal, a sub-bacia apresenta vertentes retilíneas mais extensas e os LV avançam até a média vertente, enquanto na margem esquerda restringem-se aos segmentos de topo, em resposta a morfologia e comprimento da rampa. O ICTS indicou que nos setores em que ocorrem essa classe de solos a superfície é estável, favorecendo a pedogênese. A espacialização dos LV está intimamente relacionada a interação entre declividade, comprimento e forma da vertente, o que se reflete nos seus principais atributos morfológicos, conforme descrito a seguir.

Tabela 4: Correspondência entre as classes de solos e as áreas de abrangência no MCS e no MDS do alto curso da sub-bacia do Córrego Quatro Pontes.

\begin{tabular}{ccc|ccc}
\hline & MCS & \multicolumn{3}{c}{ MDS } \\
\hline Classes & $\mathrm{Km}^{2}$ & Área (\%) & Classes & $\mathrm{Km}^{2}$ & Área (\%) \\
LV & 15,6 & $44,0 \%$ & LV & 7,6 & 21,5 \\
NV & 16,9 & $47,7 \%$ & NV & 22,4 & 63,4 \\
GX & 0,91 & $2,5 \%$ & GX & 0,5 & 1,5 \\
RR+RL+CX & 2,0 & $5,6 \%$ & RR+RL+CX & 4,74 & 13,4 \\
\hline
\end{tabular}

Os LV identificados em campo apresentam sequência de horizontes Ap, AB, BA, Bw1 e Bw2, com transição em superfície plana e gradual e em subsuperfície plana e difusa. Os horizontes latossólicos $(\mathrm{Bw})$ são predominantemente vermelhoescuro-acinzentados (10R 3/4), muito argilosos, com estrutura primária em blocos subangulares e secundária em granular, com grau de desenvolvimento forte, consistência ligeiramente dura (seco) e friável (úmido). A ocorrência de estruturas granulares fortemente desenvolvidas está de acordo com a natureza oxídica desses horizontes latossólicos (KER, 1997). A atividade da fauna em campo foi observada por meio da presença de biotúbulos alongados e retilíneos nos horizontes subsuperficiais e de formigas e térmitas nos horizontes
Ap e AB, BA e Bw1.

A classe de solo com maior percentual de representatividade em ambos os mapeamentos, em área, foi a dos NV. No MCS os NV representam 47,7\% da sub-bacia $\left(16,9 \mathrm{~km}^{2}\right)$ e no MDS $63,4 \%\left(22,4 \mathrm{~km}^{2}\right)$. Tanto no MCS como no MDS, os NV associam-se, principalmente, aos segmentos médios e baixos da vertente, podendo também ocorrer nos fundos de vale (Figura 6). Na margem direita ou segmento leste da sub-bacia, os NV apresentam área de abrangência semelhantes em ambos os mapeamentos. Já na margem esquerda ou setor oeste, o NV apresenta maior área de abrangência no MDS. Os segmentos de vertente ocupados pelos NV no MDS apresentam declividades superiores a $3-20 \%$, formas com curvaturas retilínea- 
côncavo e retilíneo-retilíneo e divergente-convexo. No MCS, os NV têm área de abrangência reduzida no setor oeste da sub-bacia, limitando-se aos segmentos de média e baixa vertente; na alta vertente, ocorrem os LV. Contudo, trata-se de um setor com vertentes de declividades mais acentuadas e com comprimento de rampa menor, quando comparado com o setor leste da sub-bacia. No MDS, os NV estão associados às classes de ICTS 2 e, eventualmente, ICTS 3, as quais indicam níveis de instabilidade da paisagem (Figura 5).

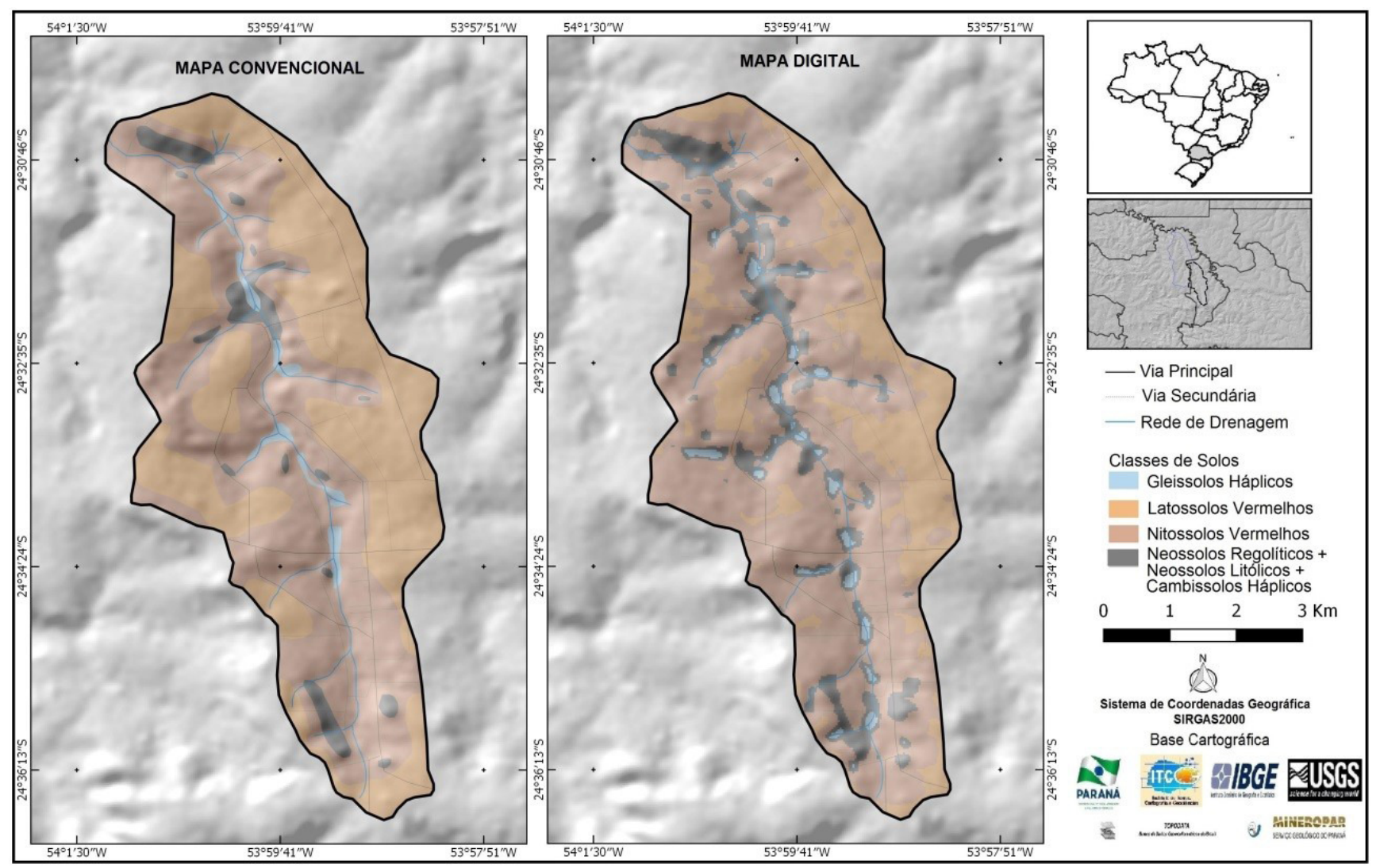

Figura 6 - Mapeamento convencional e digital de solos do alto curso da sub-bacia do Córrego Quatro Pontes.

Os NV, via de regra, apresentam coloração vermelhoescuro-acinzentada $(10 \mathrm{R} 3 / 2 ; 3 / 3)$ e sequência de horizontes: Ap, AB, B nítico1, B nítico 2 e Bw. A estrutura é do tipo blocos angulares a subangulares multifacetados, com grau de desenvolvimento moderado a forte e de consistência dura (seco) e friável a muito firme (úmido). A ocorrência de cerosidade forte e abundante evidencia o processo de translocação de argila para o horizonte B nítico e/ou rearranjo das partículas das unidades estruturais, em resposta aos ciclos de umedecimento e secamento, conforme preconizado pela EMBRAPA (2013).

A associação (RR + RL + CX) representa 5,6\% $\left(2,0 \mathrm{~km}^{2}\right)$ da área no MCS e 13,4\% $\left(4,74 \mathrm{~km}^{2}\right)$ no MDS. Essa associação ocorre em segmentos da vertente próximos aos canais fluviais, relacionada ao aumento na dissecação do terreno e aprofundamento do talvegue, com declividades superiores a $20 \%$, predominantemente. Não raro, esses solos ocorrem em setores de vertente com declividades inferiores a $20 \%$ e rupturas de declive curtas, por exemplo. Essa associação também ocorre em setores de jusante da sub-bacia, associada ao ICTS 3. Nessas condições pedogeomorfológicas é natural que a intensidade e a velocidade dos processos pedogenéticos sejam reduzidas em relação as posições estáveis da paisagem. Isto desfavorece a formação de solos mediante à pedogênese regressiva (GERRARD, 1993).

A interação entre a declividade, a curvatura da vertente e o ITCS foram determinantes para a definição dos limites espaciais e compreensão da organização vertical e lateral dos RL na paisagem. Via de regra, esses solos apresentaram sequência de horizontes A, $\mathrm{CR}$ e R com ocorrência de rocha fragmentada dentro de $40 \mathrm{~cm}$ (contato lítico fragmentário). O horizonte CR, é constituído por mais de $70 \%$ de fragmentos de rocha, nas frações cascalho e calhaus $(<20 \mathrm{~cm})$, predominantemente, e pouco material pedogeneizado. Ainda, nos segmentos 
com declividade entre $20 \%$ e $45 \%$, foi descrito um perfil de RR, com sequência de horizontes Ap, AC, CR e R e contato lítico entre 70 e $90 \mathrm{~cm}$ (léptico). Nos RL e RR predominou a cor bruno-amarelada-escura (5YR 3/4). Esses seguimentos da vertente estão associados às classes de ICTS 3 e caracterizam-se como áreas instáveis da paisagem, o que contribui para a ocorrência de solos rasos, como os RL e RR ou, ainda, os CX.

Os CX foram encontrados em segmentos de vertente com formas côncavas e declividade entre $8 \%$ e $20 \%$, predominantemente. Esses solos possuem sequência de horizontes $\mathrm{Ap}, \mathrm{Bi}, \mathrm{Cr}$ e $\mathrm{CR}$, em que o horizonte $\mathrm{Bi}$ franco-argilo-siltoso apresentou espessura $>15 \mathrm{~cm}$, coloração bruno-avermelhada-escura $(2,5 \mathrm{YR}$ $3 / 4,3 / 3$ ), estrutura em blocos subangulares, pequena e fraca. Cerca de 5\% de seu volume são constituídos por fragmentos de rocha intemperizada.

Os GX são os solos menos representativos, quando comparados com as demais ordens de solos. No mapa convencional, os GX ocorreram em 2,5\% da área do alto curso da sub-bacia, enquanto que no mapa digital representaram $1,5 \%$. Predominam nos setores planos dos fundos de vale, comumente relacionadas à declividade entre 0 e $3 \%$, curvaturas convergentesretilínea, retilíneas-retilínea e convergentes-côncava, assim como em áreas que apresentaram ICTS 1. Esses solos são argilosos a muito argilosos a partir da superfície e apresentam sequência de horizontes $\mathrm{Ag}, \mathrm{Cg} 1$ e $\mathrm{Cg} 2$. Nesses setores de fundo de vale (com declividades < $3 \%$ ), os fluxos hídricos subsuperficiais, incluindo o lençol freático, concentram-se em profundidades menores que $70 \mathrm{~cm}$, a partir da superfície, devido ao contato lítico e a forma convergente-côncava-retilínea da vertente, criando condições para saturação de água. Essa saturação varia de acordo com as estações do ano, conforme evidenciada pela formação de mosqueados amarelo-avermelhados
(7,5YR 6/8) e acinzentados (5YR 4/1) na matriz do solo.

De modo geral, os LV e os NV estão associados aos setores mais estáveis da vertente, enquanto os RR, RL e CX ocorrem nos setores instáveis. Os GX dominam os segmentos agradacionais da vertente, conforme constatado a partir da relação entre os atributos topográficos e a distribuição das unidades mapeadas.

\subsection{Concordância espacial entre o MCS e o MDS}

A diferença nos resultados apresentados pelo MCS (mapa de referência) e o MDS foi uma das informações obtidas por meio da matriz de erros. O cruzamento indicou concordância de $66 \%$ entre os mapas (Tabela 5). A classe de solos que obteve valores mais elevados de concordância espacial foi a dos LV. Os valores de Erros do Usuário (EU) aproximaram-se dos 100\%, destacando-se que não foram incluídos pixels referentes aos GX, o que contribuiu para a melhor concordância. Em relação ao Erro do Produtor (EP), o percentual de acerto ficou abaixo do esperado (48\%), pois $52 \%$ dos pixels referentes aos LV do MCS foram mapeados como NV no MDS. Os diferentes resultados obtidos entre o MDS e o MCS referem-se aos pesos atribuídos no primeiro. O MDS possuí limites diretamente relacionados as expressões algébricas definidas previamente. No caso, os LV estavam condicionados as declividades de $0-3 \%$, ICTS 1 e as classes específicas de curvatura de terreno. A menor área de LV, na margem esquerda da sub-bacia (setor oeste), está relacionada a declividade superior a $3 \%$ em que o peso atribuído foi de valor 2. Dessa forma, os limites dos LV se restringem aos setores específicos da paisagem (topo), com declividade fraca. Em campo, a transição entre os LV e os NV na vertente não é facilmente identificável. Em setores com declividade entre 3 e $6 \%$ podem ocorrer $\mathrm{LV}$ ou NV, dependendo do comprimento da vertente, variável não utilizada neste trabalho.

Tabela 5: Matriz de erros da álgebra entre o MDS e o MCS do alto curso da sub-bacia do Córrego Quatro Pontes.

\begin{tabular}{|c|c|c|c|c|c|c|c|c|}
\hline \multirow{2}{*}{\multicolumn{2}{|c|}{ Matriz de Erros }} & \multicolumn{7}{|c|}{ MDS } \\
\hline & & $\mathbf{L V}$ & $\mathbf{N V}$ & GX & $\mathbf{R R}+\mathbf{R L}+\mathbf{C X}$ & Total & Eom & $\mathbf{E P}$ \\
\hline \multirow{7}{*}{$\underbrace{\infty}$} & $\mathbf{L V}$ & 7.057 .643 & 7.499 .311 & 101.367 & 17.196 & 14.675 .517 & $52,0 \%$ & $48,0 \%$ \\
\hline & NV & 201.828 & 13.320 .645 & 2.604 .757 & 360.213 & 16.487 .443 & $19,0 \%$ & $81,0 \%$ \\
\hline & GX & 0 & 461.580 & 1.545 .839 & 16.291 & 2.023 .710 & $23,6 \%$ & $76,3 \%$ \\
\hline & $\mathbf{R R}+\mathbf{R} \mathbf{L}+\mathbf{C X}$ & 20.816 & 198.208 & 309.530 & 131.233 & 659.787 & $80,0 \%$ & $20,0 \%$ \\
\hline & Total & 7.280 .287 & 21.479 .744 & 4.561 .493 & 524.934 & \multicolumn{3}{|c|}{ Total de pixels $=33.846 .458$} \\
\hline & Eic & $3,0 \%$ & $38,0 \%$ & $66,0 \%$ & $75,0 \%$ & \multirow{2}{*}{\multicolumn{3}{|c|}{$\mathrm{EG}=66,0 \%$}} \\
\hline & $\mathbf{E U}$ & $97,0 \%$ & $62,0 \%$ & $34,0 \%$ & $25,0 \%$ & & & \\
\hline
\end{tabular}

Obs: Eom-Erros de omissão; EP-Erros do produtor; Eic-Erros de inclusão; EU-Erros do Usuário; EG-Exatidão Global. 
A concordância espacial entre os NV apresentou taxa de acerto, referente ao EU, superior a $60 \%$, enquanto que os resultados obtidos de EP representou acerto de $81 \%$. No que tange aos erros de inclusão, destaca-se que a classe com maior quantidade de pixels incluídos foi a dos LV e a classe dos GX foi a principal responsável em elevar os valores de omissão no grupo dos NV. A presença mais expressiva de NV no MDS deve-se aos pesos atribuídos. Tais solos foram associados às áreas com ICTS $2 \mathrm{e}$ declividades de 3 a $20 \%$. Isso explica a maior área de NV na margem esquerda da sub-bacia (setor oeste), em que a declividade é mais forte e os setores de topo e interflúvios são menores ou com vertentes mais curtas. Em campo, os NV estão distribuídos espacialmente numa faixa entre a alta e a baixa vertente, em setores de declividade mais forte, podendo avançar até o fundo dos vales.

A concordância espacial dos GX indicou 34\% de acerto nos valores de EU. Isto pode ser entendido em função da discordância espacial com a classe dos $\mathrm{NV}$, onde foram incluídos mais de $60 \%$ dos pixels classificados como NV. De outro lado, os valores de EP apresentaram mais de $70 \%$ de acerto, embora a classe dos NV tenha contribuído para reduzir tais acertos. No MDS os GX foram definidos principalmente pela curvatura do terreno, em que a forma convergentecôncava da vertente possuía peso 3 . Os demais pesos foram de ICTS 1 e em local de baixa declividade.

Os valores referentes ao EU e ao EP da associação $\mathrm{RR}+\mathrm{RL}+\mathrm{CX}$ apresentaram taxas de concordância mais baixas quando comparados com os resultados obtidos com as demais unidades de mapeamento. A concordância de EU foi de $25 \%$, de modo que a principal classe incluída foi a dos NV. Em relação ao EP, a taxa de concordância foi de $20 \%$, o que pode ser creditado a omissão de $80 \%$ dos pixels, sendo principalmente classificados como GX e NV no MDS. No MDS a associação $\mathrm{RR}+\mathrm{RL}+\mathrm{CX}$ foi definida em função das declividades superiores a $8 \%$, ICTS 3 e formas convergente-côncavo e retilíneo-côncavo. Os baixos valores de EU e EP podem ser atribuídos à diferença de representatividade espacial dessa unidade entre os mapas, sendo que no MCS a área dessa associação é menor do que no MDS.

Os valores de correspondência entre o MCS e o MDS, obtidos neste trabalho (66\%), foram próximos dos obtidos por outros autores. Silva (2017) obteve $66 \%$ de correspondência espacial entre o MDS e o MCS na Folha Topográfica de Marechal Cândido Rondon-PR.
Nowatzki (2013) alcançou 65\% de correspondência para a bacia hidrográfica do Rio Pequeno. Silveira et al. (2012) obteve valores mais satisfatórios (69\%) para a bacia do arroio do Corvo, enquanto Sirtoli et al. (2008a, b) alcançaram correspondência de $66 \%$ para a bacia do rio Canguiri. Chagas et al. (2017) também obtiveram valores de correspondência acima de $60 \%$ ao comparar vários modelos pedométricos com o MCS numa bacia hidrográfica em região serrana do Rio de Janeiro.

\section{Considerações Finais}

Os resultados obtidos indicam que o MDS é uma opção viável para contribuir com a produção de mapas de solos em escala detalhada, como por exemplo, 1:50.000. A concordância de $66,0 \%$ entre o MCS e o MDS indica que os pesos e as variáveis ainda devem ser explorados para a obtenção de resultados mais precisos. As discordâncias encontradas no trabalho devem-se à atribuição dos pesos às variáveis utilizadas e, também, às peculiaridades geomórficas da área. Nota-se que no MDS, os pesos atribuídos às variáveis utilizadas definiram a área de abrangência de cada classe de solos. No caso dos LV, sua extensão foi determinada pela declividade (menor que 3\%) e ICTS 1, restringindo-se às áreas de topo e divisores de água e, em alguns casos, até a média vertente. Por sua vez, os NV foram associados às áreas de declividades entre 3 e $20 \%$ e ICTS 2 , o que superestimou sua presença no MDS. As demais classes tiveram discordâncias também associadas aos pesos atribuídos.

Demais variáveis topográficas, além daquelas utilizadas neste trabalho (declividade, curvatura do terreno e ICTS), como, por exemplo, a variável comprimento de rampa, podem auxiliar na distinção dos limites entre os LV e os NV. O índice topográfico de umidade também pode contribuir para a obtenção de resultados mais coerentes com a realidade, no que se refere à identificação de setores da paisagem com saturação hídrica. Por fim, os resultados alcançados revelam que o MDS é uma alternativa viável ao levantamento de solos, tanto em termos financeiros como de recursos humanos, em escala que permite seu uso para o manejo e conservação em abrangência municipal ou em termos de sub-bacias hidrográficas. A atual disponibilidade de dados geomorfométricos, aliada às técnicas de pedometria, constituem importantes meios para ampliar e detalhar as informações sobre da 
distribuição espacial dos solos, quando comparados com o MCS. Entretanto, as aferições em campo continuam sendo etapas indispensáveis em qualquer tipo de levantamento e mapeamento de solos.

A difusão de dados de RPA (Aeronaves Pilotadas Remotamente) é outro potencial instrumento que agiliza e otimiza os custos e o tempo do trabalho de espacialização dos solos em escala de detalhe. A utilização desses recursos deve ser ampliada, considerando-se as particularidades dos dados e de cada paisagem (geologia, relevo, clima, etc.), para também definir metodologias que consigam alcançar resultados satisfatórios de acordo com as peculiaridades de cada área. Em todos os casos, entende-se que as incursões em campo para a validação dos dados são essenciais para assegurar a confiabilidade dos resultados.

\section{Agradecimentos}

A CAPES/FUNDAÇÃO ARAUCÁRIA pela concessão de bolsa para o primeiro autor e a instituição pela infraestrutura física disponibilizada.

\section{Referências Bibliográficas}

BADE, M.R. et al. Compartimentação geomorfológica das bacias hidrográficas do Paraná III (Brasil/Paraguai). Revista Brasileira de Geografia Física, 9:1370-1383, 2016.

BHERING, S. B. et al. Mapa de solos do estado do Paraná: legenda atualizada. 2007.

BRUNGARD, C. W. et al. Machine learning for predicting soil classes in three semi-arid landscapes. Geoderma, p.68-83, 2015.

BURROUGH, P.A. The technologic paradox in soil survey: new methods and techniques of data capture and handling. In: ZINCK, J.A. (Ed.) Soil survey: perspectives and strategies for the 21st century. The Netherlands: ITC Publication, Enschede, p.15-23, 1993.

CALEGARI, M.R.; MARCOLIN, L. Relação solo-paisagem na bacia da Sanga Matilde Cuê, Marechal Cândido Rondon (PR). Boletim de Geografia, 32:110-121, 2014.

CHAGAS, C.S. et al. Data mining methods applied to map soil units on tropical hillslopes in Rio de Janeiro, Brazil. Geoderma Regional v.9, p.47-55, 2017.

DANZER, M. Relação solo-relevo na Subunidade Morfoescultural de Nova Santana Rosa - PR. Dissertação (Mestrado em Geografia) - Universidade Estadual do Oeste do Paraná, Marechal Cândido Rondon, 2015. 76p.
DEBELLA-GILO, M.; ETZELMÜLLER, B. Spatial prediction of soil classes using digital terrain analysis and multinomial logistic regression modeling integrated in GIS: examples from vestfold county. Catena 77, p. 8-18, 2009.

DOBOS, E. et al. Digital soil mapping as a support to production of functional maps. EUR $22123 \mathrm{EN}$. Office for Official Publications of the European Communities, Luxemburg, 2006.

EMBRAPA. Levantamento de reconhecimento de solos do Estado do Paraná: Tomo I e II. (Org.) LARACH, J.; CARDOSO, A.; CARVALHO, A.P.; HOCHMÜLER, D.P.; FASOLO, P.J.; RAÜEN, M.J. Curitiba: EMBRAPA - SNLCS/ SUDESUL/IAPAR. 1984.

EMBRAPA. Procedimentos normativos de levantamentos pedológicos. (Org.) SANTOS, H. G et al. Brasília, 1995, 122p.

EMBRAPA. Sistema brasileiro de classificação de solos. 3 ed. Brasília: Embrapa; Rio de Janeiro: Embrapa Solos, 2013, 353p.

EWALD, K. H.; FERNANDES, O. V. Q. (2012). Espessura dos derrames vulcânicos da formação da Serra Geral no município de Marechal Cândido Rondon/Paraná. In: FABRINI, J. E.; DIAS, E. S. (Org.). Dinâmica Territorial e Ambiental e Espaço de Fronteira. 4. ed. Cascavel: EDUNIOESTE, p. 257-267.

GERRARD, J. Soil geomorphology: present dilemmas and future challenges. Geomorphology, 7, p.61-84, 1993.

GESSLER, P.E., et al. Modeling soil-landscape and ecosystem properties using terrain attributes. Soil SCI.SOC. AM. J. vol. 64, 2000.

JANJAR, C. Variações morfopedológicas da unidade de paisagem de Bela Vista, município de Marechal Cândido Rondon - PR. Geografia em Questão, v. 06, p. 221-234, 2013.

LEPSCH, I. F. As Necessidades de efetuarmos Levantamentos Pedológicos Detalhados no Brasil e de estabelecermos as Séries de Solos. Revista Tamoios, v. 9, n. 1, p. 3-15, 2013.

LIMA, L. A. S. et al. Soil mapping of a small watershed in a brazilian savanna biome: a semi-automatic approach. Journal of Geographic Information System, v. 06, p. 79-87, 2014.

KEMPEN, B. et al. Efficiency comparison of conventional and digital soil mapping for updating soil maps. Soil Sci. Soc. Am. J. v.76, p. 2097-2115, 2011.

KER, J.C. Latossolos do Brasil: uma revisão. Geonomos, 5:1740, 1997.

MAGALHÃES, V.L.; NÓBREGA, M.T.; CUNHA, J.E. Transformações pedológicas no platô de Marechal Cândido 
Rondon (PR). Ambiência Guarapuava, 8:633-649, 2012.

MAGALHÃES, V.L. Gênese e evolução de sistemas pedológicos em unidades da paisagem do município de Marechal Cândido Rondon - PR. Tese (Doutorado em Geografia) - Universidade Estadual de Maringá, Maringá, 2013, 123p.

McBRATNEY, A.B. et al. An overview of pedometric techniques for use in soil survey. Geoderma, 97: 293-327, 2000.

McBRATNEY, A.B.; SANTOS, M.L M.; MINASNY, B. On digital soil mapping. Geoderma, 117: 3-52, 2003.

MINEROPAR. O Grupo Serra Geral no estado do Paraná: mapeamento geológico na escala de 1:250.000 (I e II). $1^{\text {a }}$ ed. Curitiba: Mineropar, v. 1 e 2, 2013.

MOORE, I.D.; GESSLER, P.E.; NIELSEN, G.A.; PETERSON, G.A. Soil attribute prediction using terrain analysis Sci. Soc. Am. J., 57:443-452, 1993.

MORESCO, M.D. Estudos de paisagem no município de Marechal Cândido Rondon - PR. Dissertação (Mestrado em Geografia) - Universidade Estadual de Maringá, Maringá, 2007, 137p.

NARDY, A.J.R. et al. Geologia e estratigrafia da Formação Serra Geral. Revista Geociências, 21:15-32, 2002.

NOWATZKI, A. Utilização de atributos topográficos no mapeamento preliminar de solos da Bacia Hidrográfica do Rio Pequeno (Antonina/PR). Dissertação (Mestrado em Geografia) Departamento de Geografia, Setor de Ciências da Terra, Universidade Federal do Paraná, Curitiba, 2013.

NOWATZKI, SANTOS, L.J.C. Mapeamento digital de solos por pedometria com base em atributos topográficos da bacia hidrográfica do Rio Pequeno - Paraná. Revista Ra'eGa, 32:185-211, 2014.

PARANÁ. Secretaria de Estado do Meio Ambiente e Recursos Hídricos. Bacias hidrográficas do Paraná: Série histórica. 2. ed. Curitiba, 2013.

POLIDORO, J. C. et al. Programa Nacional de Solos do Brasil (PronaSolos). Rio de Janeiro: Embrapa Solos, 53p., 2016.

ROCHA, A.S. et al. Relações morfopedológicas nos setores de fundos de vale da bacia hidrográfica do córrego Guavirá, Marechal Cândido Rondon - PR. Boletim de Geografia, Maringá, v. 30, p. 99-110, 2012.

SANTOS, L.J.C. et al. Mapeamento geomorfológico do Estado do Paraná. Revista Brasileira de Geomorfologia, 2006.

SANTOS, R.D. et al. Manual de descrição e coleta de solo no campo. 6. ed. Viçosa: Sociedade Brasileira de Ciência do Solo, 2013, 100p.

SILVA, B.A. Caracterização geoambiental do trecho superior do córrego Quatro Pontes, município de Quatro Pontes Paraná - Brasil. Monografia (Trabalho de conclusão de curso) - Universidade Estadual do Oeste do Paraná, Marechal Cândido Rondon, 2014, 68p.

SILVA, B. A.; DANZER, M. ; MARTINS, V. M.; HAYAKAWA, E. H. Mapeamento geoambiental do alto curso da bacia hidrográfica do Córrego Quatro Pontes - PR. Perspectiva Geográfica, v.9, 2016, p.1 16.

SILVA, B. A. Mapeamento convencional e digital de solos na folha topográfica de Marechal Cândido Rondon - PR - Brasil. Dissertação (Mestrado em Geografia) Universidade Estadual do Oeste do Paraná, Campus de Marechal Cândido Rondon - PPGG, 2017a, 92p.

SILVA, B. A. Atributos morfométricos do terreno como base para o mapeamento de solos no município de Quatro Pontes, Paraná - Brasil. In - Anais IV Geofronteiras. UFGD, 2017b, 10p (ISSN: 2362-3365).

SILVEIRA, C.T. Análise digital do relevo na predição de unidades preliminares de mapeamento de solos: Integração de atributos topográficos em Sistemas de Informações Geográficas e redes neurais artificiais. Tese (Doutorado em Geografia) - Universidade Federal do Paraná, Curitiba, 153p., 2010 .

SILVEIRA, C.T. et al. Pedometria apoiada em atributos topográficos com operações de tabulação cruzada por álgebra de mapas. Revista Brasileira de Geomorfologia, 13:125-137, 2012.

SILVEIRA, C.T. et al. Soil prediction using artificial neural networks and topographic attributes. Geoderma, 165-172, 2013.

SIRTOLI, A.E. et al. Atributos do relevo derivados de modelo digital de elevação e suas relações com solos. Scientia Agraria, 9:317-329, 2008a.

SIRTOLI, A.E. et al. Atributos topográficos secundários no mapeamento de pedoformas. Geociências, 21:63-77, 2008b.

USGS, United States Geological Survey. Disponível em https:// earthexplorer.usgs.gov/. Acessado em agosto de 2017.

VALERIANO, M.M. Topodata: guia para utilização de dados geomorfológicos locais. São José dos Campos, SP. INPE: Coordenação de Ensino, Documentação e Programas Especiais, 2008. 